This item was submitted to Loughborough's Research Repository by the author.

Items in Figshare are protected by copyright, with all rights reserved, unless otherwise indicated.

\title{
Influence of cell and collagen concentration on the cell-matrix mechanical relationship in a corneal stroma wound healing model
}

PLEASE CITE THE PUBLISHED VERSION

https://doi.org/10.1016/j.exer.2010.07.013

\section{PUBLISHER}

(c) Elsevier

\section{VERSION}

NA (Not Applicable or Unknown)

\section{PUBLISHER STATEMENT}

This work is made available according to the conditions of the Creative Commons Attribution-NonCommercialNoDerivatives 4.0 International (CC BY-NC-ND 4.0) licence. Full details of this licence are available at: https://creativecommons.org/licenses/by-nc-nd/4.0/

\section{LICENCE}

CC BY-NC-ND 4.0

\section{REPOSITORY RECORD}

Ahearne, Mark, Samantha L. Wilson, Kuo-Kang Liu, Saaeha Rauz, Alicia J. El Haj, and Ying Yang. 2019.

"Influence of Cell and Collagen Concentration on the Cell-matrix Mechanical Relationship in a Corneal Stroma Wound Healing Model”. figshare. https://hdl.handle.net/2134/26832. 
1 Title page

2 Influence of cell and collagen concentration on the cell-matrix mechanical relationship

3 in a corneal stroma wound healing model

4 Mark Ahearne, ${ }^{\text {a }}$ Samantha L. Wilson, ${ }^{\mathrm{a}}$ Kuo-Kang Liu, ${ }^{\mathrm{b}}$ Saaeha Rauz, ${ }^{\mathrm{c}}$ Alicia J.El Haj ${ }^{\mathrm{a}}$ and

$5 \quad$ Ying Yang*a

6 anstitute of Science and Technology in Medicine, School of Medicine, Keele University,

7 Thornburrow Drive, Hartshill, Stoke-on-Trent, ST4 7QB, UK

8 b School of Engineering, University of Warwick, Coventry CV4 7AL, UK

9 c Academic Unit of Ophthalmology, School of Immunity and Infection, University of

10 Birmingham, Birmingham B18 7QU, UK

11

12 *Corresponding author. Ying Yang; Tel.: p44 (0) 1782554 606; fax: p44 (0) 1782747319.

13 E-mail address: bea00@keele.ac.uk

15 Research highlights

- Non-destructively measuring the modulus of corneal fibroblasts in hydrogel for 25 days.

17

- Initial hydrogel and cell concentration affect the contraction and modulus increase.

- Hydrogels with high initial cell seeding densities increased in elastic modulus faster.

19 - Hydrogels with low initial collagen concentrations increased in elastic modulus faster. 


\section{Abstract}

2 The effect of different collagen and cell concentrations on the mechanical and remodeling

3 behaviors of corneal stroma wound healing models consisting of collagen hydrogels seeded

4 with human corneal fibroblasts during a 25 day culture period were examined. Human

5 corneal fibroblasts were seeded at $1 \times 10^{5}, 3 \times 10^{5}$ or $5 \times 10^{5}$ cells per hydrogel, and collagen

6 concentrations of $2.5 \mathrm{mg} / \mathrm{ml}, 3.5 \mathrm{mg} / \mathrm{ml}$ or $4.5 \mathrm{mg} / \mathrm{ml}$ were examined. Two non-destructive

7 techniques, spherical indentation and optical coherence tomography, were used to measure

8 the elastic modulus and dimensional changes respectively at several time-points over the

9 culture period. The elastic modulus of the hydrogels increased continuously over 25 days.

10 Hydrogels with higher initial cell seeding densities and lower initial collagen concentrations

11 were found to increase in elastic modulus faster and possessed a higher elastic modulus by

12 the end of the culture period when compared to the other hydrogels. A mathematical equation

13 was applied to accurately fit the change in elastic modulus over time. This study

14 demonstrates a robust in vitro technique able to monitor the effect of different parameters on

15 the cell-matrix mechanical relationship in a corneal stroma model during prolonged culture

16 periods and enhances our understanding on corneal wound healing processes.

18 Keywords:

19 Corneal stroma; corneal fibroblasts; corneal biomechanics; collagencell-matrix interactions;

20 wound healing 


\section{1. Introduction}

2 Examination of corneal fibroblasts in vitro in three-dimensional environments can provide a

3 useful model for understanding the cell behavior in vivo after injury. In laser eye surgery,

4 there is an interest in how the procedure results in corneal thinning and how the creation of a

5 corneal flap may risk corneal ectasia. Scar tissue formation results from phenotypic changes

6 in keratocyte behavior after injury which leads to extracellular matrix contraction. Some

7 corneal diseases are influenced by the collagen structure in the stroma, such as keratoconus in

8 which structural changes within the cornea results in stromal thinning and a more conical

9 shape than its normal aspherical curve. Hydrogels have been used to replicate extracellular matrix by providing a three-dimensional structure through which cells can survive, move and

11 communicate (Bell et al., 1979). Collagen based hydrogels have become particularly popular

12 for replicating corneal extracellular matrix in vitro because of their viscoelastic

13 characteristics, similar composition to native cornea, their biocompatibility and their ability 14 to be remodeled by cells (Kim et al., 2010; Duan et al., 2007). Fibroblasts seeded in collagen hydrogels have been shown to influence the mechanical and structural characteristics of such hydrogels (Bell et al., 1979, Ahearne et al., 2010, Philips et al., 2003). Fibroblasts can

17 manipulate the mechanical properties of their surrounding hydrogel matrix through a number

18 of mechanisms including the release of extracellular matrix products and matrix digestion enzymes (Webb et al., 2006, Saddiq et al., 2009), attachment and integration of fibroblasts throughout the hydrogels (Takakuda and Miyairi, 1996) and contraction of the hydrogels

21 (Bell et al., 1979). Changes to the mechanical properties of the matrix can in turn induce a

22 change in the cell’s behavior (Pelham and Wang, 1997, Engler et al., 2006, Breuls et al., 23 2009). This creates a reciprocal cell-matrix mechanical relationship where both cell behavior 24 and matrix properties are dependent upon each other (Wakatsuki and Elson, 2003, Brown, 25 2006). 
1 There are many factors that can influence the cells' abilities to manipulate the mechanical

2 properties of their surroundings. It has been shown that the addition of matrix

3 metalloproteinases inhibitors (Daniels et al., 2003) and other reagents can influence the cell-

4 matrix mechanical relationship. Chemical and photochemical crosslinking of matrix

5 components such as collagen can also be used to influence mechanical characteristics

6 (Cheung et al., 1985, Ahearne et al., 2008a). Mechanical stimulation of cells has been shown

7 to affect the ability of cells to change their surrounding matrix (Nirmalanandhan et al., 2008).

8 In addition to these factors, the initial conditions used to manufacture the hydrogels also play

9 an important role in dictating the cell-matrix mechanical relationship. For cell-seeded

10 collagen hydrogels this may include the number of cells seeded and the collagen

11 concentration used to produce them.

12 One of the difficulties in examining the cell-matrix mechanical relationship is that there are

13 few methods for monitoring the changes in their mechanical behavior over long cell culture

14 periods. Recently a novel online spherical indentation technique has been developed to non-

15 destructively monitor the changes in elastic modulus of hydrogels over several weeks in

16 culture (Ahearne et al., 2010). A non-destructive imaging technique, optical coherence

17 tomography (OCT), has also been developed to reveal and monitor the morphology of three-

18 dimensional cell culture samples during prolonged culture periods (Ahearne et al., 2008b). In

19 this study, the role of initial cell seeding density and collagen concentration on the

20 mechanical and contractile behavior of collagen hydrogels has been examined using these

21 two techniques over a 25 day culture period. 


\section{2. Materials and methods}

\section{2.1. Sample preparation}

3 All chemicals used were from Sigma-Aldrich unless otherwise stated. Human corneal tissue

4 was used to cultivate corneal fibroblasts as previously described (Ahearne et al., 2005). This

5 research has received approval from Black Country Research Ethics Committee

6 (06/Q2702/44) and informed consent has been obtained. Hydrogels with a total volume of

$7500 \mu l$ were manufactured with rat-tail collagen type 1 (BD Bioscience, Erembodegem,

8 Belgium) using a previously described protocol (Ahearne et al., 2008a). Human corneal

9 fibroblasts were suspended inside the collagen hydrogel solution prior to gelation. Collagen

10 concentrations of $2.5 \mathrm{mg} / \mathrm{ml}, 3.5 \mathrm{mg} / \mathrm{ml}$ and $4.5 \mathrm{mg} / \mathrm{ml}$ and cell concentrations of $5 \times 10^{5}, 3 \times$

$1110^{5}$ and $1 \times 10^{5}$ cells per hydrogel were examined. Hydrogels without cells were also

12 manufactured as a control. The hydrogels were cultured in six-well plates with $5 \mathrm{ml}$ culture

13 media per well consisting of low glucose Dulbecco’s Modified Eagle’s Medium

14 supplemented by $10 \%$ fetal calf serum, 1\% l-glutamine and 1\% antibiotic-antimycotic

15 solution. The media was changed every 3-4 days.

\section{2.2. Characterization of elastic modulus and dimension changes}

17 A sample holder was built to hold the hydrogels during mechanical measurements (Fig. 1A).

18 The hydrogels were suspended between two transparent plastic circular rings of inner

19 diameter $20 \mathrm{~mm}$. The rings were held in place between two thin stainless steel plates. The

20 lower base plate had a number of screws attached which were used to keep the sample holder

21 together. Three hydrogels could be held in a single sample holder at any one time. Each

22 sample holder was assembled in phosphate buffered saline (PBS) within a large rectangular

23 Petri dish in a Class II laminar flow hood followed by incubation at $37^{\circ} \mathrm{C}$. A multi-LED

24 lamp was placed in the incubator to illuminate the sample. The hydrogels were deformed 
1 using a PTFE sphere (Insley, Berks, UK) of diameter $4 \mathrm{~mm}$. The sphere was placed in the

2 centre of each hydrogel. The weight $(0.072 \mathrm{~g})$ of the sphere caused the hydrogel to deform.

3 After measurements had taken place, the sphere was removed. The hydrogel was taken out

4 from the sample holder and then placed back in culture medium until the next measurement

5 time-point. An image acquisition system was used to record images of the spherically

6 deformed hydrogels (Ahearne et al., 2005). It consisted of a long-working-distance objective

7 microscope (Edmund Industrial Optics, York, UK) with a computer-linked CCD camera

8 (XC-ST50CE, Sony, Japan). The camera was linked to an image acquisition card (National

9 Instruments, USA) which was used to acquire and process the images. An example of a

10 hydrogel deformation image acquired by this system is shown (Fig. 1B). This system allowed

11 images to be recorded of the deformation profile of the hydrogel from outside the incubator

12 through a glass window. The magnification of the system was calibrated with the computer-

13 acquired images of a stage micrometer. Images of the spherically deformed hydrogels were

14 recorded 10 min after the sphere was initially placed onto the hydrogel. This was to allow

15 time-dependent deformation to reach equilibrium. The elastic modulus was measured one day

16 after hydrogel formation and every 3-4 days subsequently for up to 25 days.

17 A home-built optical coherence tomography (OCT) system was used to examine the cross-

18 sectional thickness of each specimen at the same examining frequency as the modulus

19 measurement. A filter paper ring around the outer edge of each hydrogel prevented

20 contraction in all directions except the thickness. OCT is a low coherence interferometric

21 technique which measures backscattered light after the light source has passed through a

22 material (Bagnaninchi et al., 2007). This technique allowed non-destructive imaging of the

23 hydrogels cross-sectional thickness to be measured under sterile conditions. A

24 superluminescent diode with a central wavelength of $1310 \mathrm{~nm}$ and bandwidth of $52 \mathrm{~nm}$ was 
1 used as the source of the OCT. The system has an axial resolution of $14 \mu \mathrm{m}$ in free space and

2 penetration depth of up to $2 \mathrm{~mm}$.

\section{2.3. Mathematical modeling}

4 The elastic modulus of the hydrogels was calculated from the images using a large

5 deformation model (Ju and Liu, 2002). From the acquired images, the central deformation $(\delta)$

6 of the hydrogel was calculated and substituted into Equation 1 to find the elastic modulus

$7 \quad 6 w r=\operatorname{Eh}\left(0.075 \delta^{2}+0.78 r \delta\right)$

9 where $h$ is the hydrogel thickness, $\mathrm{r}$ is the radius of the sphere and $\mathrm{w}$ is the weight of the 10 sphere. This equation is applicable when the ratio of $a / r=5$ and $\delta / r<1.7$, where a is the

11 radius of the clamped portion of the hydrogel. This model also assumes that the ratio of 12 thickness to the radius is low and the deformation is large, hence stretching of the membrane 13 dominates over bending.

14 A simple equation was used to simulate the change in elastic modulus with respect to culture 15 time as shown in Equation 2

$16 \quad E_{c}=E_{0} e^{\alpha t}$

18 where $E_{c}$ is the elastic modulus of the cell-seeded hydrogels, $E_{0}$ is the equivalent elastic modulus of the hydrogel with the same initial collagen concentrations but without cells, $\alpha$ is a constant and $t$ is the culture time in days. The constant $\alpha$ can be calculated using regression

21 analysis and is dependent on the initial cell and collagen concentration used. When no cells 22 are present in the hydrogel $\alpha=0$, therefore $E c=E 0$. 


\section{$1 \quad$ 2.4. MTT assay}

2 Methylthiazolyldiphenyl-tetrazolium bromide (MTT) was used to monitor cell proliferation

3 within the hydrogels. MTT was dissolved in PBS at a concentration of $5 \mathrm{mg} / \mathrm{ml}$ and sterile

4 filtered. Each hydrogel examined was placed into a cell culture well containing 10\% MTT

5 solution in culture media. The wells were placed into an incubator at $37^{\circ} \mathrm{C}, 5 \% \mathrm{CO}_{2}$ for $3 \mathrm{~h}$.

6 The MTT/culture media was removed and each hydrogel was washed twice in PBS. DMSO

7 solution was then added to each well for $1 \mathrm{~h}$. The DMSO solution was transferred into a 96

8 well plate and the absorbance of light at wavelengths of $570 \mathrm{~nm}$ and $690 \mathrm{~nm}$ were measured

9 using a microplate reader (Synergy 2, BioTek, USA). Readings were obtained at the two wavelengths of $570 \mathrm{~nm}$ and $690 \mathrm{~nm}$ and were subtracted from each other to give single values

11 for each well. A standard curve was created by suspending a known numbers of cells in a

12 hydrogel. From the standard curve, the number of viable cells was calculated.

\section{2.5. Fluorescence staining and cell viability}

14 Cell viability was assessed using a live-dead cell double staining kit. The kit contained

15 Calcein-AM and Propidium Iodide which fluorescently stain live cells green and dead cells

16 red respectively. $2 \mu 1$ of Calcein-AM and $1 \mu 1$ Propidium Iodide in $500 \mu$ PBS were added to

17 each hydrogel and incubated for 20 min at $37^{\circ} \mathrm{C}$. The cells were examined using an FV300

18 confocal microscope (Olympus, Japan). To fluorescently stain f-actin, a phalloidin-TRITC

19 staining solution was applied to hydrogel specimens following the manufacturers protocol.

20 The stained cells were viewed by confocal microscopy.

\section{2.6. Statistical analysis}

22 ANOVA (Minitab, USA) was used to find which of the factors under investigation were

23 statistically significant with 95\% confidence interval. 


\section{3. Results}

2 Cell proliferation was examined using MTT (Fig. 2). Cells were shown to have proliferated

3 by 3-4 times their original cell number in all the hydrogels after 7 days in culture. This

4 proliferation along with hydrogel contraction led to a dramatic increase in the cell density, i.e.

5 the number of cells per unit volume of hydrogel, especially for the hydrogel group with 3.5

$6 \mathrm{mg} / \mathrm{ml}$ collagen concentration (Fig. 2A). The cell density from hydrogels seeded with $1 \times 10^{5}$,

$73 \times 10^{5}, 5 \times 10^{5}$ cells per hydrogel increased to approximately $4 \times 10^{5}, 9 \times 10^{5}, 18 \times 10^{5}$ cells

8 per hydrogel respectively. Hydrogels with a lower initial collagen concentration appeared to

9 show a greater increase in cell proliferation when compared to hydrogels with higher initial collagen concentration but the same cell seeding concentration. The group of the hydrogels

11 that were seeded with $5 \times 10^{5}$ cells (Fig. $2 B$ ) showed less change in cell population between

127 and 25 days. Hydrogels with $1 \times 10^{5}$ and $3 \times 10^{5}$ cells continued to proliferate between 7

13 and 25 days but at a slower rate. Interestingly, hydrogels with lower initial collagen concentration ( $2.5 \mathrm{mg} / \mathrm{ml}$ and $3.5 \mathrm{mg} / \mathrm{ml})$ but the highest cell seeding density, $5 \times 10^{5}$, showed a decrease in cell population between 7 and 25 days. These hydrogels had more dead cells than the $4.5 \mathrm{mg} / \mathrm{ml}$ hydrogels (Fig. 2C and D).

17 The effect of cell seeding concentration on the elastic modulus of the hydrogels was examined (Fig. 3). Measurements were taken of hydrogel samples run in parallel ( $n=6$ for each group). Cell seeding densities of $5 \times 10^{5}$, $3 \times 10^{5}$ and $1 \times 10^{5}$ cells per hydrogel were examined as well as hydrogels without cells. Higher cell seeding concentrations led to a

21 faster and more substantial increase in elastic modulus. Regardless of the initial collagen concentration used, the hydrogels with the highest number of cells $\left(5 \times 10^{5}\right)$ had the highest modulus after 25 days. Two-way ANOVA showed that cell seeding concentration had a

24 significant effect on the change in elastic modulus with culture time. Hydrogels with higher 25 cell concentrations also decreased in thickness more quickly than those with lower cell 
1 concentrations. The higher cell number resulted in more extensive contraction of the

2 hydrogels which caused a reduction in water content. The increased contraction and reduction

3 in volume of the hydrogels resulted in higher cell and collagen densities.

4 The effect of initial collagen concentration $(2.5 \mathrm{mg} / \mathrm{ml}, 3.5 \mathrm{mg} / \mathrm{ml}$ and $4.5 \mathrm{mg} / \mathrm{ml})$ on the

5 elastic modulus of the hydrogels was also examined. Measurements were again taken of

6 hydrogel samples run in parallel ( $n=6$ for each group). Hydrogels with the lowest initial

7 collagen concentration had a faster rate of increase in elastic modulus (Fig. 3A-C). These

8 hydrogels were more contractile than hydrogels with a higher collagen concentration (Fig.

9 3D-F). The increased rate of contraction led to an increase in cell density and collagen density. Two-way ANOVA showed that the initial collagen concentration of cell-seeded

11 hydrogels had a significant effect on the change in elastic modulus over the culture period.

12 Representative actin staining images are demonstrated in Fig. 4. At week 4 when collagen concentration was fixed $(3.5 \mathrm{mg} / \mathrm{ml})$, higher cell seeding density resulted in less organized

14 and less strong actin filament expression (Fig. 4 A-C); whilst when cell density was fixed 15 (500,000 cells), lower collagen concentration in the specimens results in less organized actin 16 expression (Fig. 4 D-F). Culture time also affect actin expression. Longer culture time 17 resulted in less actin organization in the specimen with lower collagen concentration (2.5 mg/ml) and higher cell density (500,000 cells) (Fig. 4 G-I), whilst actin organization improved in higher collagen concentration $(4.5 \mathrm{mg} / \mathrm{ml})$ and lower cell density (100,000 cells)

20 (Fig. 4 J-L) hydrogels.

21 Equation 2 was used to plot the change in elastic modulus over the culture period from the

22 data for different cell and collagen concentrations. The values for the constant $\alpha$ and the 23 correlation coefficient R (in brackets) are displayed in Table 1. The value of $\alpha$ was dependent on the cell and collagen concentrations used to manufacture the hydrogels. As can be seen in 
$1 \quad$ Fig. 3 the rate of increase in elastic modulus over time was influenced by the initial cell and

2 collagen concentrations. When there was no or little change in the elastic modulus the value

3 of $\alpha$ approached zero.

\section{4. Discussion}

5 We have demonstrated an online approach to monitoring the cell-matrix mechanical

6 relationship in cell-seeded hydrogels which may be used as a corneal stroma wound healing

7 model. The non-destructive nature of the spherical indentation technique described here

8 allowed repeated measurement of the hydrogels at different time-points. OCT allowed

9 repeated online measurement of the hydrogels thickness. The combination of these two

10 techniques provides an excellent approach to examine the remodeling behavior and the cell-

11 matrix mechanical relationship in a corneal stroma model over several weeks in culture. This

12 approach is also useful in the development of a tissue engineered corneal substitute since it

13 can be used to monitor the mechanical changes in the samples over a prolonged culture

14 period.

15 Hydrogels seeded with cells provide a useful model for understanding cell behavior and

16 tissue remodeling. Collagen provides the most suitable hydrogel material for examining these

17 behaviors since it can be easily remodeled and collagen type 1 is the most abundant protein in

18 the cornea. Previous work using agarose and alginate hydrogels showed limited remodeling

19 by corneal cells (Ahearne et al., 2005). Hydrogels seeded with corneal fibroblasts have been

20 used to model the corneal stroma and in particular stromal wound healing and remodeling

21 behaviors (Kim et al., 2010, Kurosaka et al., 1998). In vitro corneal fibroblasts behave

22 similarly to activated keratocytes after corneal injury (Fini, 1999). These cells are more

23 contractile than inactivated keratocytes and exhibit fibroblastic characteristics. It has

24 previously been reported that corneal fibroblasts affect the elastic modulus of collagen 
1 hydrogels through a number of mechanisms including by integrating themselves throughout

2 the hydrogels, attaching and applying intrinsic strain in the hydrogels and releasing

3 extracellular matrix products (Ahearne et al., 2010). The attachment and application of force

4 by corneal fibroblasts results in contraction of the surrounding matrix. This contraction

5 directly affects the hydrogels properties by removing water and increasing the overall

6 collagen density which in turn affect the elastic modulus and thickness of the hydrogels.

7 Hence any factors which influence hydrogel contraction by fibroblasts in our corneal stroma

8 models, such as the cell seeding concentration or collagen concentration, will speed up or

9 slow down the changes of these properties.

10 Awad et al. (2000) and Nirmalanandhan et al. (2006) found that increasing the number of

11 cells led to an increased rate of collagen contraction although both also found that there was a

12 maximum threshold where increasing the number of cells no longer had any affect. Our

13 experiments showed that increasing the number of cells resulted in an increased rate of

14 contraction, a faster increase in elastic modulus and a higher modulus value was obtained at

15 any given culture time-point. This phenomenon can be explained by the increased attachment

16 points to collagen matrix due to higher cell numbers. As the hydrogels contract, water is

17 pushed out of the hydrogel leading to an increase in collagen density and an increase in

18 overall stiffness. In addition, cells attach and spread themselves throughout the hydrogel

19 forming an integral part of the hydrogels structure and mechanical properties. Since cells

20 respond to strain when attached to a matrix (Dartsch et al., 1986, Petroll et al., 2004) and

21 stress fibers found in cells are substantially stiffer than the hydrogels (Deguchi et al., 2006), it

22 is not surprising that increasing the number of cells led to an increase in elastic modulus of

23 the hydrogels once these cells had attached themselves.

24 The initial collagen concentration used was found to affect the ability of cells to change the

25 mechanical properties of the hydrogels. A higher initial collagen concentration resulted in a 
1 higher initial stiffness for the hydrogels. However, the initial collagen concentration also

2 affected the rate of hydrogel contraction with a lower collagen concentration allowing a faster

3 rate of contraction. This faster rate of contraction led to these hydrogels having a higher cell

4 density and a higher overall collagen density by the end of the culture period. This

5 phenomenon demonstrates a clear mechano-feedback response between fibroblasts and the

6 matrix. In wound healing, fibroblast-generated tension compacts newly deposited collagen

7 into a dense aligned matrix in order to carry muscle and loads (Brown, 2006). Hydrogels with

8 a low initial collagen concentration had less mechanical resistance when fibroblasts

9 contracted the matrix hence the contraction became easier and faster compared to hydrogels

10 with higher initial collagen concentrations. Increasing the cell density increases the amount of

11 force which can be generated to contract the hydrogels.

12 A relationship was to found to exist between cell proliferation and elastic modulus of the

13 hydrogel. Our data shows that cells proliferated over the first week in culture in all the

14 samples tested. This increase in cell number led to an increase in cell density which in turn

15 increased the amount of contraction and led to a higher overall elastic modulus. Between day

167 and day 25, the total number of viable cells was reduced in hydrogels seeded with $5 \times 10^{5}$

17 cells except those of initial concentration $4.5 \mathrm{mg} / \mathrm{ml}$ in which the contraction of the hydrogel

18 was low. This suggests that the more contractile hydrogels were less able to maintain cell

19 proliferation and viability compared to the less contractile hydrogels. The live/dead staining

20 experiments confirmed that the hydrogels seeded with $5 \times 10^{5}$ cells and an initial collagen

21 concentration of $2.5 \mathrm{mg} / \mathrm{ml}$ had more dead cells than those with an initial collagen

22 concentration of $4.5 \mathrm{mg} / \mathrm{ml}$. The increased rate of contraction would have resulted in

23 additional strain being applied to the cells and also increased the overall cell density, both of

24 which could have resulted in reduced cell viability. These results were consistent with our

25 previous study in which the addition of a matrix metalloproteinases (MMP) inhibitor, 
1 ilomastat, to the hydrogels restricted contraction and led to higher cell viability in comparison

2 to the controls (Duan et al., 2007). This proposes a hypothesis that increased strain and

3 overpopulation of cells that results from contraction in hydrogels can reduce cell viability. A

4 more comprehensive study could be carried out in the future to directly relate cell

5 proliferation with changes in elastic modulus and thickness of the hydrogels, although the

6 large number of cells required for MTT makes this study complicated.

7 The expression pattern of actin filaments mirrored well the mechanical properties of the

8 hydrogels and the cell proliferation and viability. Hydrogels with low cell densities due to a

9 low initial cell seeding number and a high initial collagen concentration experienced the most contraction and displayed higher modulus. At the early culture time, these specimens showed

11 dense and aligned actin filaments. By the 4th week, cells in the hydrogels exhibited thin actin

12 filaments and no particular cell alignment, manifesting as distorted actin expression. This

13 could be due to the reduction in cell viability in these samples. The least contracted specimens in which lower modulus has been measured displayed highly organized and dense actin filament by week 4 .

The change in elastic modulus over the culture period was accurately represented using our mathematical equation. The constant $\alpha$ in the equation (2) can be used to describe the influence of initial cell seeding concentration and collagen concentration on the stiffness of the hydrogel. When $\alpha$ is large, the rate of modulus increase is greater than when $\alpha$ is small. When $\alpha$ reads zero, the hydrogels will not change in modulus. The application of such

21 equations is useful in estimating the elastic modulus at time-points which were not directly measured and predicting when a particular elastic modulus was reached.

23 In summary, the two non-destructive techniques described here enabled observations of the reciprocal mechanical influence between the cell and matrix in a corneal stroma wound 
1 healing model for several weeks in culture. This approach greatly enhances our ability to

2 understand corneal tissue remodeling, wound healing behavior and the formation of

3 connective tissue by tissue engineering principles. The mechanical properties of the

4 surrounding environment can affect cell behavior in collagen constructs by regulating cell

5 proliferation (Hadjipanayi et al., 2009), matrix production (Karamichos et al., 2008) and

6 matrix remodeling (Bell et al., 1979, Nirmalanandhan et al., 2006). Hence this study

7 demonstrates a good in vitro model revealing cell-matrix interactions over prolonged culture

8 periods.

9

10 


\section{Acknowledgements}

2 Sample holders were donated by KMF Precision Sheet Metal, (Newcastle-under-Lyme, UK).

3 This research was funded by BBSRC (BB/F002866/1). The Academic Unit of

4 Ophthalmology is supported by the Birmingham Eye Foundation (Registered (UK) Charity 5 257549).

\section{Conflict of Interest Statement}

7 The authors whose names are listed on the title page certify that they have NO affiliations

8 with or involvement in any organization or entity with any financial interest (such as

9 honoraria; educational grants; participation in speakers' bureaus; membership, employment,

10 consultancies, stock ownership, or other equity interest; and expert testimony or patent-

11 licensing arrangements), or non-financial interest (such as personal or professional

12 relationships, affiliations, knowledge or beliefs) in the subject matter or materials discussed

13 in this manuscript. 


\section{References:}

2 Ahearne, M., Liu, K.K., El Haj, A.J., Then, K.Y., Rauz, S., Yang, Y., 2010. Online

3 monitoring of the mechanical behaviour of collagen hydrogels: influence of corneal

4 fibroblasts on elastic modulus. Tissue Eng. C 16, 319e327.

5 Ahearne, M., Yang, Y., Then, K.Y., Liu, K.K., 2008a. Non-destructive mechanical

6 characterization of UVA/riboflavin crosslinked collagen hydrogels. Br. J. Ophthalmol. 92,

$7 \quad 268 \mathrm{e} 271$.

8 Ahearne, M., Bagnaninchi, P.O., Yang, Y., El Haj, A.J., 2008b. Online monitoring of

9 collagen fibril alignment in tissue-engineered tendon by PSOCT. J. Tissue Eng. Regen. Med.

$10 \quad 2,521 \mathrm{e} 524$.

11 Ahearne, M., Yang, Y., El Haj, A.J., Then, K.Y., Liu, K.K., 2005. Characterizing the

12 viscoelastic properties of thin hydrogel-based constructs for tissue engineering applications. J.

13 R. Soc. Interface 2, 455e463.

14 Awad, H.A., Bulter, D.L., Harris, M.T., Ibrahim, R.E., Wu, Y., Young, R.G., Kadiyala, S.,

15 Boivin, G.P., 2000. In vitro characterization of mesenchymal stem cell seeded collagen

16 scaffolds for tendon repair: effects of initial seeding density on collagen kinetics. J. Biomed.

17 Mater. Res. 51, 233e240.

18 Bagnaninchi, P.O., Yang, Y., Zghoul, N., Maffulli, N., Wang, R.K., El Haj, A.J., 2007.

19 Chitosan microchannel scaffolds for tendon tissue engineering characterized using optical

20 coherence tomography. Tissue Eng. 13, 323e331.

21 Bell, E., Ivarsson, B., Merrill, C., 1979. Production of a tissue-like structure by contraction of 22 collagen lattices by human fibroblasts of different proliferation potential in vitro. Proc. Natl.

23 Acad. Sci. U. S. A. 76, 1274e1278. 
1 Breuls, R.G.M., Klumpers, D.D., Everts, V., Smit, T.H., 2009. Collagen type V modulates

2 fibroblast behavior dependent on substrate stiffness. Biochem. Biophys. Res. Commun. 380,

$3425 \mathrm{e} 429$.

4 Brown, R., 2006. Cytomechanics in connective tissue repair and engineering. In: Chaponnier,

5 C., Desmouliere, A., Gabbiani, G. (Eds.), Tissue Repair, Contraction and the Myofibroblast.

6 Springer, New York, pp. 7e24.

7 Cheung, C.T., Natasha, P., Ko, E.C., Nimni, M.E., 1985. Mechanism of crosslinking of

8 proteins by glutaraldehyde: III. Reaction with collagen in tissue. Connect. Tissue Res. 13,

$9 \quad 109 \mathrm{e} 115$.

10 Daniels, J.T., Cambrey, A.D., Occleston, N.L., Garrett, Q., Tarnuzzer, R.W., Schultz, G.S.,

11 Khaw, P.T., 2003. Matrix metalloproteinase inhibition modulates fibroblast mediated matrix

12 contraction and collagen production in vitro. Invest. Ophthalmol.Vis. Sci. 44, 1104e1110.

13 Dartsch, P.C., Hämmerle, H., Betz, E., 1986. Orientation of cultured arterial smooth muscle

14 cells growing on cyclically stretched substrates. Acta Anat. 125, $108 \mathrm{e} 113$.

15 Deguchi, S., Ohashi, T., Sato, M., 2006. Tensile properties of single stress fibers isolated

16 from cultured vascular smooth muscle cells. J. Biomech. 39, $2603 e 2610$.

17 Duan, X., McLaughlin, C., Griffith, M., Sheardown, H., 2007. Biofunctionalization of

18 collagen for improved biological response: scaffolds for corneal tissue engineering.

19 Biomaterials 28, 78e88.

20 Engler, J., Sen, S., Sweeney, H.L., Discher, D.E., 2006. Matrix elasticity directs stem cell

21 lineage specification. Cell 126, 677e689.

22 Fini, M.E., 1999. Keratocyte and fibroblast phenotypes in the repairing cornea. Prog. Retin.

23 Eye Res. 18, 529e551. 
1 Hadjipanayi, E., Mudera, V., Brown, R.A., 2009. Close dependence of fibroblast proliferation

2 on collagen scaffold matrix stiffness. J. Tissue Eng. Regen. Med. 3, 77e84.

3 Ju, B.F., Liu, K.K., 2002. Characterizing viscoelastic properties of thin elastomeric

4 membrane. Mech. Mater. 34, 485e491.

5 Karamichos, D., Skinner, J., Brown, R., Mudera, V., 2008. Matrix stiffness and serum

6 concentration effects matrix remodelling and ECM regulatory genes of human bone marrow

$7 \quad$ stem cells. J. Tissue Eng. Regen. Med. 2, 97e105.

8 Kim, A., Lakshman, N., Karamichos, D., Petroll, W.M., 2010. Growth factor regulation of

9 corneal keratocyte differentiation and migration in compressed collagen matrices. Invest.

10 Ophthalmol. Vis. Sci. 51, 864e875.

11 Kurosaka, H., Kurosaka, D., Kato, K., Mashima, Y., Tanaka, Y., 1998. Transforming growth

12 factor-beta 1 promotes contraction of collagen gel by bovine corneal fibroblasts through

13 differentiation of myofibroblasts. Invest. Ophthalmol. Vis. Sci. 39, 699e704.

14 Nirmalanandhan, V.S., Levy, M.S., Huth, A.J., Butler, D.L., 2006. Effects of cell seeding 15 density and collagen concentration on contraction kinetics of mesenchymal stem cell-seeded 16 collagen constructs. Tissue Eng. 12, $1865 \mathrm{e} 1872$.

17 Nirmalanandhan, V.S., Shearn, J.T., Juncosa-Melvin, N., Rao, M., Gooch, C., Jain, A., 18 Bradica, G., Butler, D.L., 2008. Improving linear stiffness of the cell-seeded collagen sponge 19 constructs by varying the components of the mechanical stimulus. Tissue Eng. A 14, $20 \quad 1883 \mathrm{e} 1891$.

21 Pelham, R.J., Wang, Y., 1997. Cell locomotion and focal adhesions are regulated by substrate 22 flexibility. Proc. Natl. Acad. Sci. U. S. A. 94, 13661e13665. 
1 Petroll, M.W., Vishwanath, M., Ma, L., 2004. Corneal fibroblasts respond rapidly to changes

2 in local mechanical stress. Invest. Ophthalmol. Vis. Sci. 45, 3466e3474.

3 Philips, J.A., Vacanti, C.A., Bonassar, L.J., 2003. Fibroblasts regulate contractile force

4 independent of MMP activity in 3D-collagen. Biochem. Biophys. Res. Commun. 312, $5 \quad 725 \mathrm{e} 732$.

6 Saddiq, Z.A., Barbenel, J.C., Grant, M.H., 2009. The mechanical strength of collagen gels

7 containing glycosaminoglycans and populated with fibroblasts. J. Biomed. Mater. Res. A 89, $8 \quad 697 \mathrm{e} 706$.

9 Takakuda, K., Miyairi, H., 1996. Tensile behaviour of fibroblasts cultured in collagen gel.

10 Biomaterials 17, 1393e1397.

11 Wakatsuki, T., Elson, E.L., 2003. Reciprocal interactions between cells and extracellular

12 matrix during remodelling of tissue constructs. Biophys. Chem. 100, 593e605.

13 Webb, K., Hitchcock, R.W., Smeal, R.M., Li, W., Gray, S.D., Tresco, P.A., 2006. Cyclic

14 strain increases fibroblast proliferation, matrix accumulation, and elastic modulus of

15 fibroblast-seeded polyurethane constructs. J. Biomech. 39, 1136e1144 


\section{Tables}

2 Table 1. Values for constant $\alpha$ for different initial collagen and cell concentrations calculated

3 by regression analysis where $\alpha$ defines the rate of change in elastic modulus during the

4 culture period in equation (2) (correlation coefficient R in brackets).

5

\begin{tabular}{|l|l|l|l|}
\hline & $2.5 \mathrm{mg} / \mathrm{ml}$ & $3.5 \mathrm{mg} / \mathrm{ml}$ & $4.5 \mathrm{mg} / \mathrm{ml}$ \\
\hline $5 \times 10^{5}$ cells & $0.0804(0.99)$ & $0.0479(0.97)$ & $0.0142(0.81)$ \\
\hline $3 \times 10^{5}$ cells & $0.0735(0.98)$ & $0.0260(0.90)$ & $0.0115(0.78)$ \\
\hline $1 \times 10^{5}$ cells & $0.0403(0.96)$ & $0.0047(0.55)$ & $0.0000(0.38)$ \\
\hline
\end{tabular}

6 


\section{Figure Captions}

2 Fig. 1. (A) Disassembled view of sample holder and hydrogels and (B) recorded image of

3 hydrogel deformation.

4

5 Fig. 2. Cell proliferation after 7 and 25 days in hydrogels with: (A) different initial cells

6 concentrations and an initial collagen concentration of $3.5 \mathrm{mg} / \mathrm{ml}$; (B) different initial

7 collagen concentrations and an initial cell concentration of $5 \times 10^{5}$ cells per hydrogel. Cell

8 viability (live cells green, dead cells red) after 25 days in hydrogels with an initial cell

9 concentration of $5 \times 10^{5}$ cells per hydrogel and an initial collagen concentration of (C) 2.5

$10 \mathrm{mg} / \mathrm{ml}$ and (D) $4.5 \mathrm{mg} / \mathrm{ml}$ (scale bar $1 / 4200 \mathrm{~mm}$ ).

Fig. 3. Elastic modulus (A-C) and thickness (D-F) of hydrogels with initial collagen concentrations of $2.5 \mathrm{mg} / \mathrm{ml}$ (A, D), $3.5 \mathrm{mg} / \mathrm{ml} \mathrm{(B,} \mathrm{E)} \mathrm{and} 4.5 \mathrm{mg} / \mathrm{ml}$ (C, F) ( $n=6$ for each

14 data point).

Fig. 4. Corneal fibroblasts in collagen hydrogels stained for f-actin: (A-C) hydrogel cultured for 28 days with $3.5 \mathrm{mg} / \mathrm{ml}$ initial collagen concentration and initial cell concentrations of $1 \times$ $10^{5}$ cells $(\mathrm{A}), 3 \times 10^{5}$ cells $(\mathrm{B})$ and $5 \times 10^{5}$ cells (C); (D-F) hydrogel cultured for 28 days with $5 \times 105$ cells initial concentration and initial collagen concentrations of 2.5 (D), 3.5 (E) and $4.5 \mathrm{mg} / \mathrm{ml}(\mathrm{F}) ;(\mathrm{G}-\mathrm{I})$ hydrogels with $2.5 \mathrm{mg} / \mathrm{ml}$ and $5 \times 10^{5}$ initial collagen and cell concentration cultured for 7 days $(\mathrm{G}), 14$ days $(\mathrm{H})$ and 28 days $(\mathrm{I})$; (J-L) hydrogels with 4.5 $\mathrm{mg} / \mathrm{ml}$ and $1 \times 10^{5}$ initial collagen and cell concentration cultured for 7 days $(\mathrm{J}), 14$ days $(\mathrm{K})$

23 and 28 days (L). The scale bar is $50 \mu \mathrm{m}$. 
$1 \quad$ Fig 1

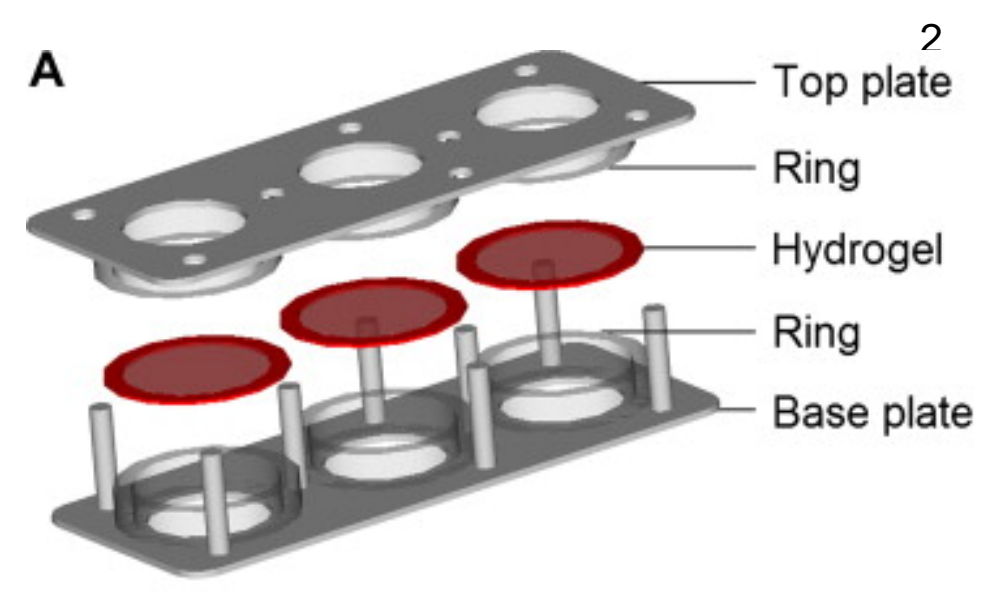

B

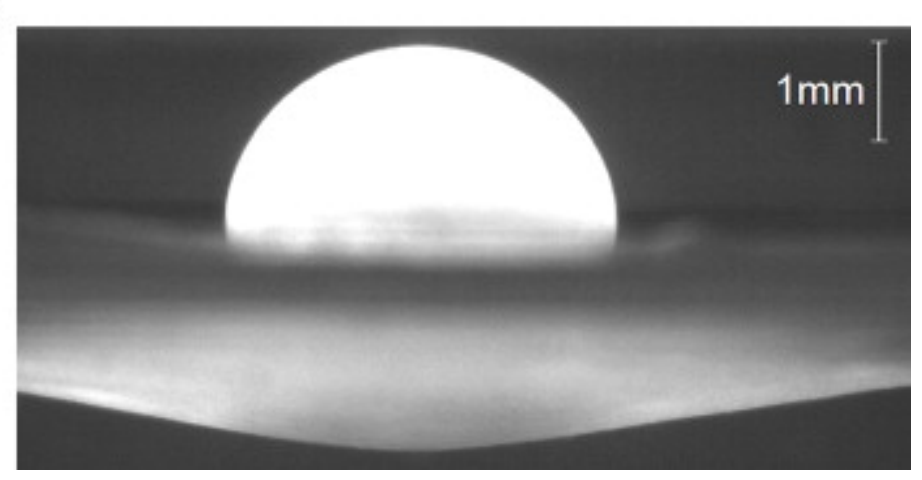




\section{$1 \quad$ Fig 2}

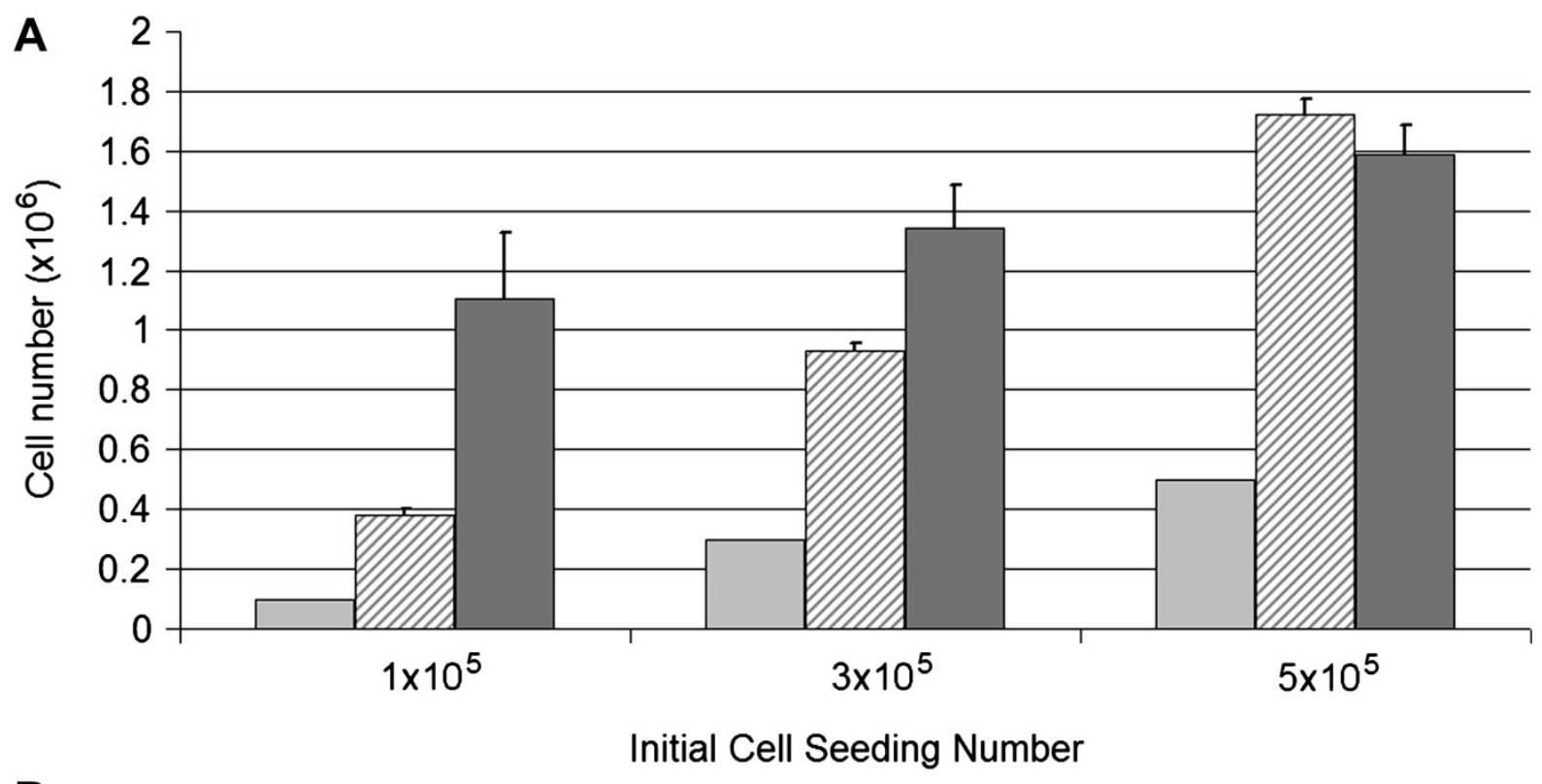

B

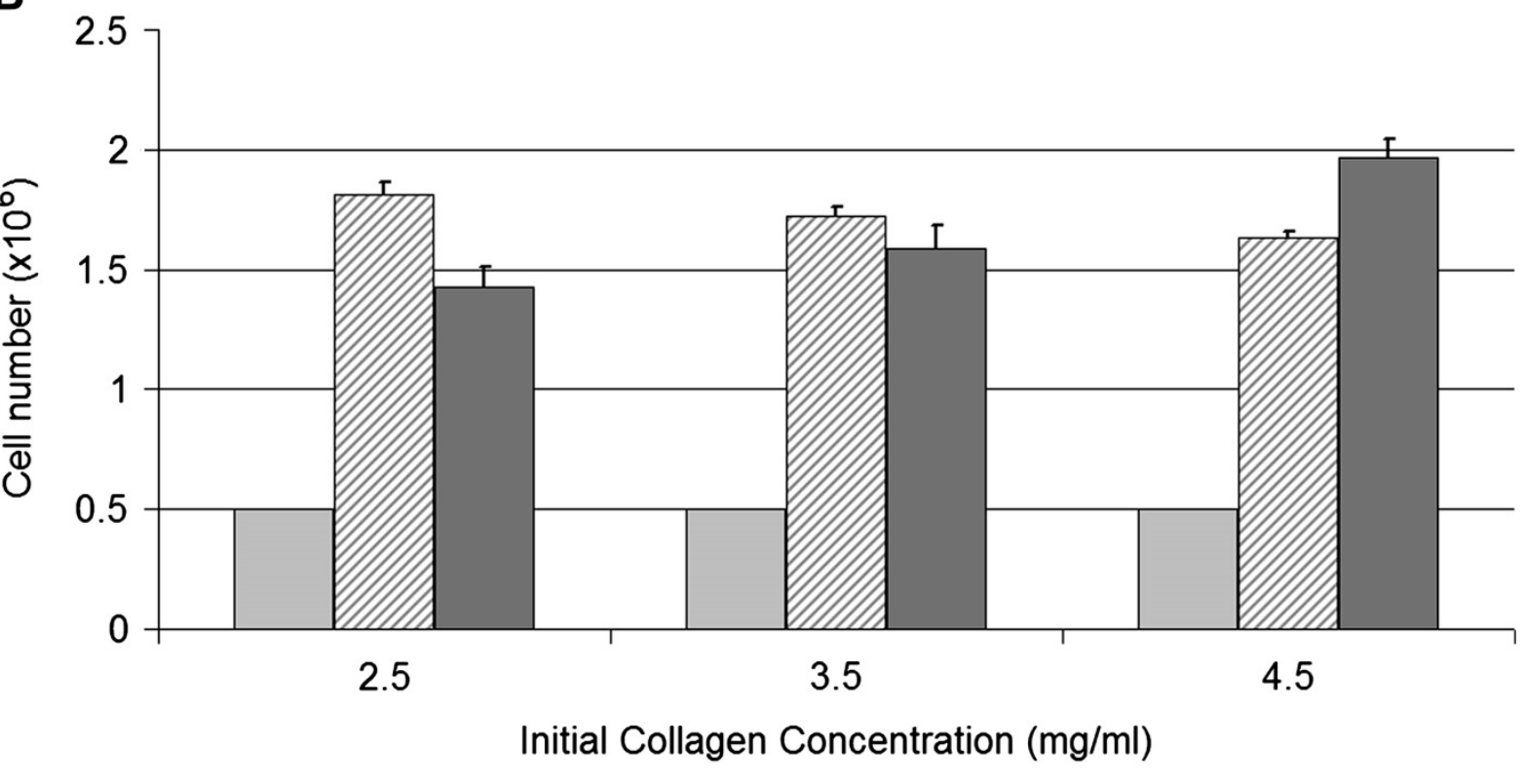

\begin{tabular}{|lll|}
\hline$\square$ Day $0 \quad \square$ Day 7 & $\square$ Day 25 \\
\hline
\end{tabular}

\section{C}

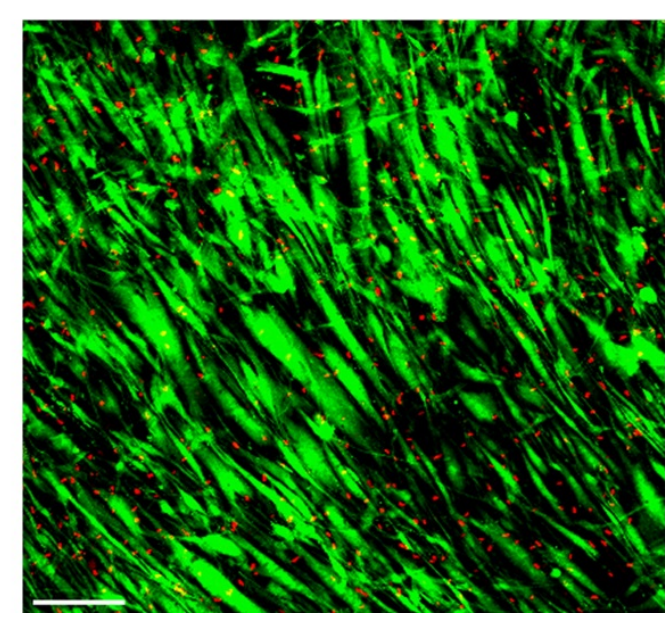

D

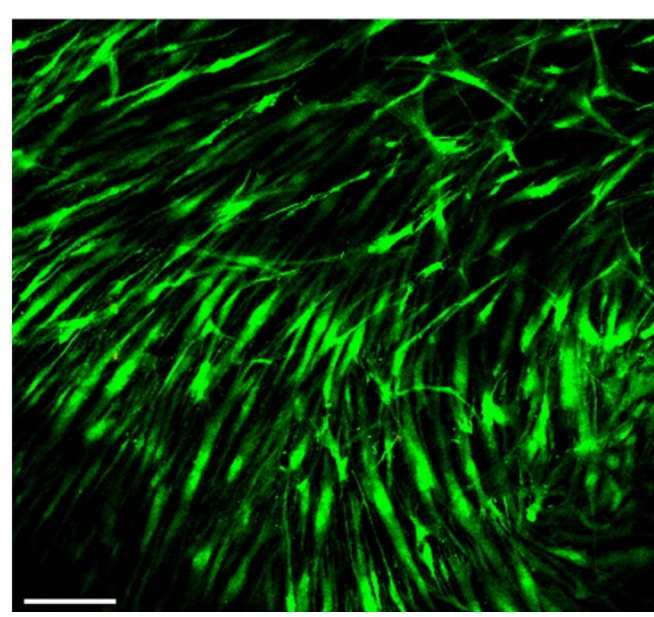



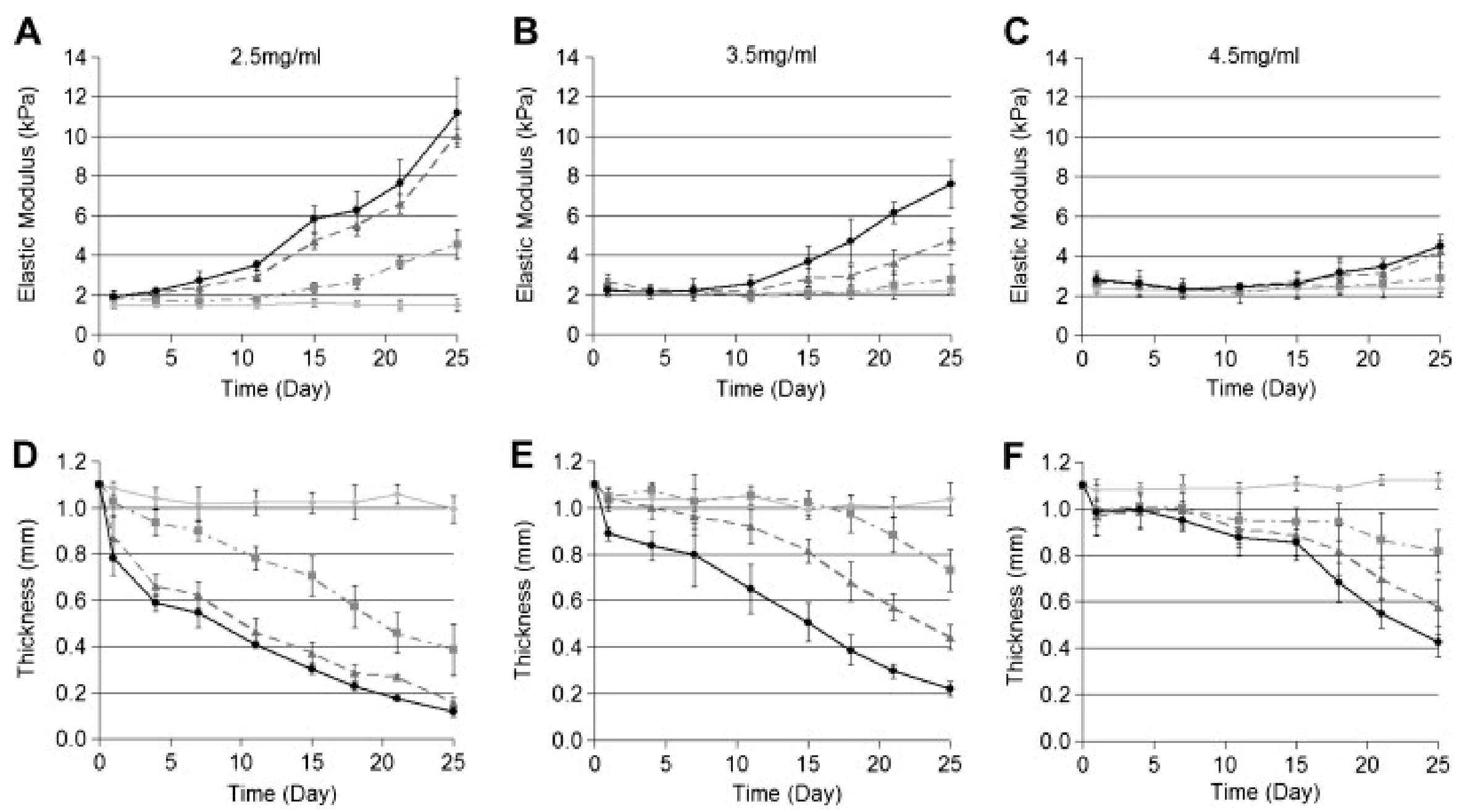

$1 \quad$ Fig 3

- no cell $--1 \times 10^{5}$ cell $-3 \times 10^{5}$ cell $\rightarrow-5 \times 10^{5}$ cell 
$1 \quad$ Fig 4

2
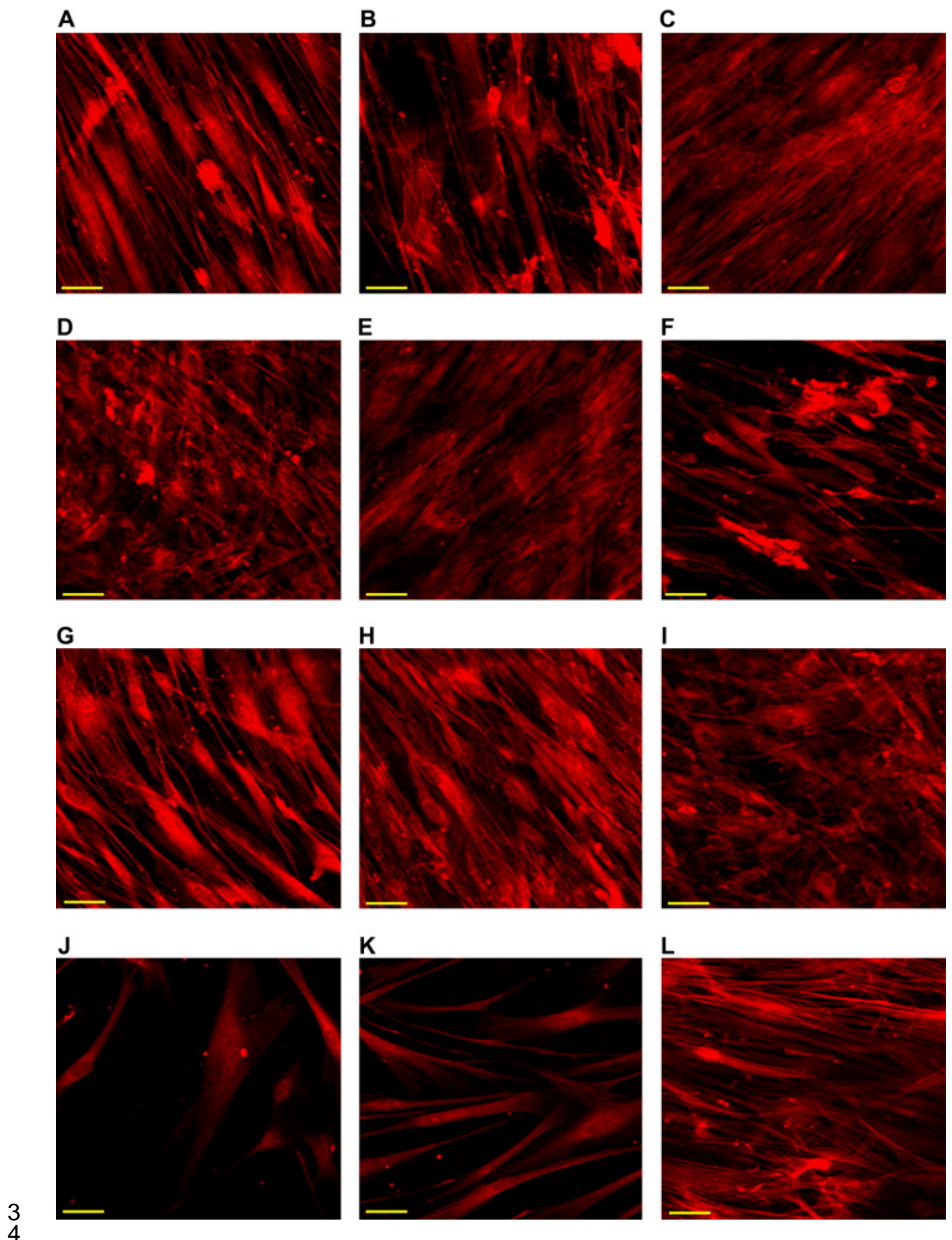
1 Graphical Abstract

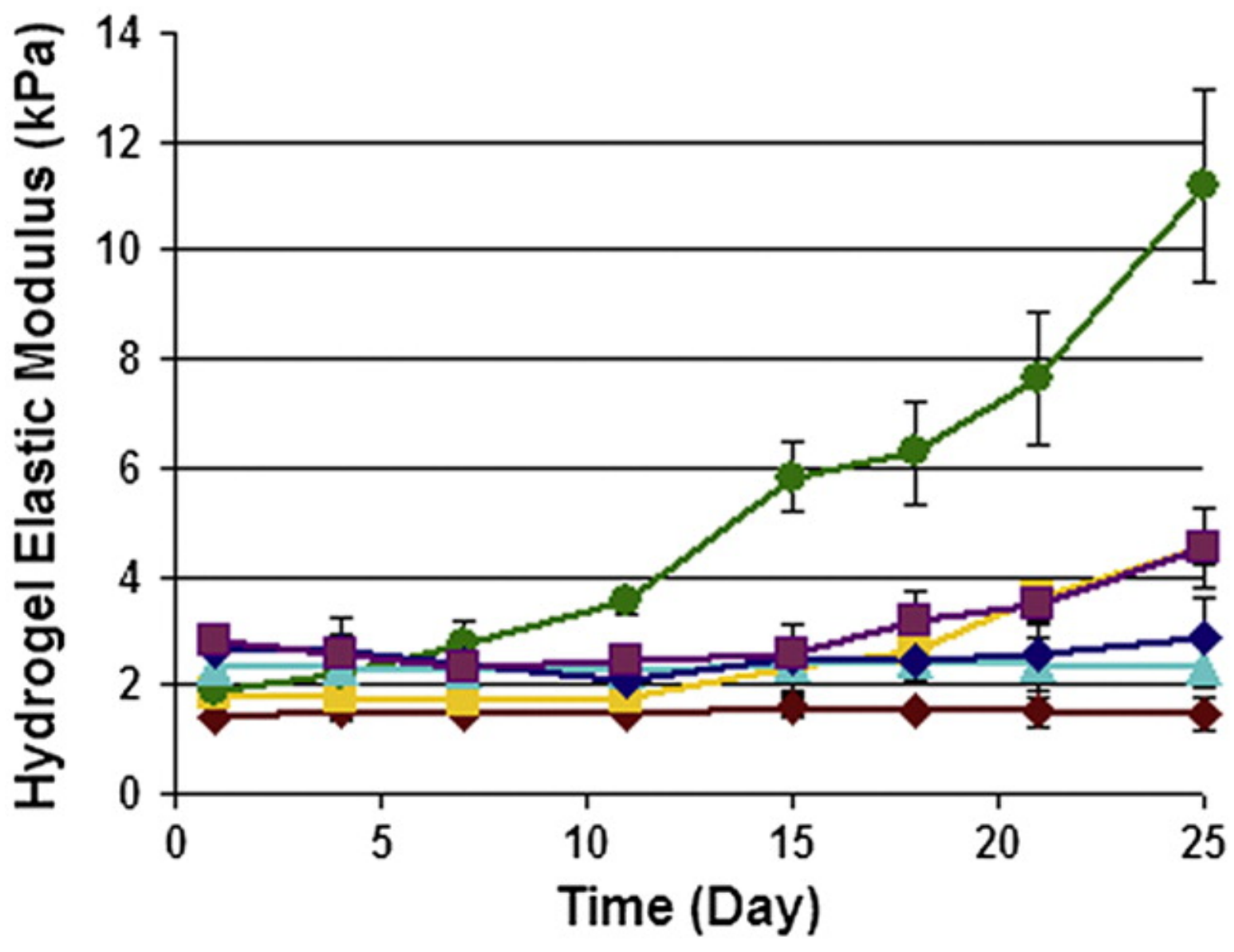

Initial collagen concentration and cell number

$\multimap-2.5 \mathrm{mg} / \mathrm{ml}$ no cell

$4.5 \mathrm{mg} / \mathrm{ml}$ no cell

$2.5 \mathrm{mg} / \mathrm{ml} 1 \times 10^{5}$ cell $\multimap 4.5 \mathrm{mg} / \mathrm{ml} 1 \times 10^{5}$ cell

$\rightarrow-2.5 \mathrm{mg} / \mathrm{ml} 5 \times 10^{5}$ cell $\rightarrow-4.5 \mathrm{mg} / \mathrm{ml} 5 \times 10^{5}$ cell 